\title{
INFECTIVITY OF LEISHMANIA PROMASTIGOTES IS ASSOCIATED WITH SURFACE ANTIGENIC EXPRESSION
}

\author{
Farrukh S. RIZVI ${ }^{1}$, Daniel AFCHAIN ${ }^{1}$, Italo SHERLOCK ${ }^{2}$, Moyses SADIGURSKY ${ }^{2}$, \\ André CAPRON ${ }^{1}$ and Ferrucio SANTORO ${ }^{1}$ \\ 'Centre d'Immunologie et de Biologie Parasitaire, Unité Mixte INSERM 167 - CNRS 624, Institut Pasteur, \\ 59019 Lille Cédex, France and ${ }^{2}$ Centro de Pesquisas Gonçalo Moniz, FIOCRUZ-UFBA, 40000 Salvador, Bahia, Brazil \\ (Received 6 June 1985) \\ (Modified version received 13 August 1985) \\ (Accepted 23 August 1985)
}

\section{Summary}

Differentiation between a non-infective and an infective Leishmania promastigote population was demonstrated. Promastigotes in the stationary phase (day 5) were found to be highly infective in vitro to $\mathrm{BALB} / \mathrm{c}$ mouse peritoneal macrophages, compared with those of the logarithmic phase (day 3). The infective promastigotes showed surface antigenic determinants different from non-infective ones. Polyclonal anti-3 day and anti-5 day antibodies were bound specifically to the surface of corresponding promastigotes in both SRIA and IFAT; no strong cross-reactions were observed otherwise. Also, polyclonal anti- 5 day but not anti- 3 day antibodies recognized efficiently the antigenic molecules on the surface of late stage (day 7) sandfly promastigotes. This clearly indicates the appearance of new antigenic molecules on the surface of infective promastigote forms. Intracellular

Key words: Leishmania - macrophage interactions - infectivity - surface antigenic expression - polyclonal antibodies .

\footnotetext{
Abbreviations: MØ, macrophage(s); GLSH, glucose lactalbumin serum hemoglobin; FCS, fetal calf serum; HEPES, $N$-2-hydroxyethyl-piperazine $N^{\prime}$-2-ethanesulphonic acid; HBSS, Hanks' balanced salt solution; FCA, Freund's complete adjuvant; PBS, phosphate buffered saline; IFAT, indirect fluorescent antibody test; FITC, fluorescein isothiocyanate; SRIA, solid phase radioimmunoassay.
}

multiplication of Leishmania was significantly inhibited by anti- 5 day antibodies compared with anti-3 day antibodies. The presence of new surface molecules on late stage promastigotes may contribute to Leishmania infectivity.

\section{Introduction}

Leishmania spp., a digenetic trypanosomatid protozoan, is an obligate intracellular parasite of mononuclear phagocytes transmitted by phlebotomine sandflies. Visceral leishmaniasis or kala-azar caused by different Leishmania species ( $L$. chagasi, $L$. donovani and $L$. infantum) is an important cause of mortality in several third world countries [1]. The parasite cycles between a flagellated promastigote stage in the insect vector and a non-flagellated intracellular amastigote stage parasitizing the mammalian phagocytic cells. Differentiation into amastigotes occurs after surface attachment and entry of promastigotes into mononuclear phagocytes. Within the cell, the parasite overcomes a formidable array of hostile activities with which macrophages (MØ) are equipped to kill ingested microbes [2]. As a similar promastigote form develops when parasites are cultured in cell-free medium [3], extensive studies have been done on Leishmania-macrophage interactions [4-8]. Most of the cellular events leading to intracellular parasitism are dependent on these interactions. 
In sandflies, Leishmania organisms undergo certain morphological and presumably functional changes to become infective promastigotes [9]. Nevertheless, it has been suggested that only a proportion of the culture promastigotes, resembling "probosis forms", are capable of invading and surviving in the $M \varnothing[4]$. Recently, a sequential development of Leishmania promastigote from a non-infective to an infective stage has been demonstrated in $L$. tropica growing in vitro and in the sandfly vector [10]. These findings raise the possibility that the development of the infective stage is associated with modifications and/or changes in antigenic expression on the surface of promastigotes. The present investigation was undertaken as a first step in this direction. In this communication we study the reactivities of anti-promastigote polyvalent immune sera against infective and non-infective stages of L. chagasi.

\section{Materials and Methods}

\subsection{Parasites}

\section{Promastigotes of $L$. chagasi}

(MHOM/BR/81/IMPERATRIZ) and $L$. donovani (MHOM/IN/83/HS70) were cultivated in monophasic GLSH medium [11] supplemented with $10 \%(\mathrm{v} / \mathrm{v})$ foetal calf serum (FCS) (Boehringer, Mannheim, F.R.G.) at $26^{\circ} \mathrm{C}$. At day 0 , cultures were inoculated with $10^{5}$ promastigotes $\cdot \mathrm{ml}^{-1}$ in $50 \mathrm{ml}$ medium and parasites were harvested at the end of day 3 and day 5 cultures. Sandfly promastigotes were obtained from the midgut of Lutzomyia longipalpis infected 7 days earlier with the Imperatriz strain of Leishmania chagasi as previously described [12]. The promastigotes were washed three times in Hanks' balanced salt solution (HBSS) supplemented with glucose before use.

\subsection{Mice and peritoneal macrophages}

BALB/c mice were bred in our animal facilities and used between 6 and $10 \mathrm{wk}$ of age. Peritoneal MØ were harvested from the unstimulated peritoneal cavity by inoculating RPMI-1640 medium (GIBCO, Auckland, New Zealand) containing $10 \%(\mathrm{v} / \mathrm{v})$ inactivated FCS, $5 \mathrm{U}$ hepa$\mathrm{rin} / \mathrm{ml}, 25 \mathrm{mM}$ HEPES $\mathrm{p} K_{\mathrm{a}}=7.5$ (SIGMA) and antibiotics $(200 \mathrm{U} / \mathrm{ml}$ penicillin, $200 \mu \mathrm{g} / \mathrm{ml}$ streptomycin). Exudates from several mice were pooled, washed and the cells seeded on coverslips placed in 24-well culture plates. Approximately $2.5 \times 10^{5}$ cells were placed in each well in RPMI-1640 with $10 \%$ FCS (pH 7.3) and cultured at $37{ }^{\circ} \mathrm{C}$ with $5 \% \mathrm{CO}_{2}$ in air to allow $\mathrm{M} \varnothing$ to settle on coverslips. After $4 \mathrm{~h}$ the non-adherent cells were washed away and wells were replaced with fresh medium.

\subsection{Leishmania-macrophage interactions}

The promastigotes harvested from 3-day (logarithmic phase) and 5-day (stationary phase)old cultures were added to the wells containing $\mathrm{M \varnothing}$ at a ratio of 20 promastigotes/cell and incubated at $37^{\circ} \mathrm{C}$ in $5 \% \mathrm{CO}_{2}$. At various time intervals ( $30 \mathrm{~min}, 24 \mathrm{~h}$ and $48 \mathrm{~h}$ ) coverslips were fixed with methanol and stained with Giemsa. At the end of $30 \mathrm{~min}$ incubation the number of promastigotes attached to the macrophages were counted in 500 cells in duplicate, and after $4 \mathrm{~h}$ incubation remaining wells were washed gently to remove the non-adherent promastigotes. The number of infected $\mathrm{M} \varnothing$ along with the number of amastigotes were counted at the end of 24 and $48 \mathrm{~h}$ incubation period. To study the inhibitory activity of polyvalent anti-sera, the promastigotes were incubated with different dilutions of either anti-3 or anti-5 day sera before invasion of the MØ.

\subsection{Immunization}

Two groups of BALB/c mice were immunized with either 3- or 5-day old $L$. chagasi promastigotes fixed with $0.1 \%$ glutaraldehyde and washed with $0.1 \mathrm{M}$ glycine buffer in HBSS. On day 0 , all mice were injected intraperitoneally with $10^{7}$ promastigotes in Freund's complete adjuvant (FCA). On days 14, 21 and 28 , the mice received subcutaneous injections of $10^{7}$ fixed promastigotes with FCA. A separate group of mice received intradermal injections of fixed promastigotes from day 14 onward. 


\subsection{Indirect immunofluorescence antibody test (IFAT)}

Three- and 5-day-old glutaraldehyde-fixed promastigotes were coated on IF slides (Institut Pasteur, Paris, France). The slides were air dried and serial dilutions of antisera were applied. After 30 min incubation at $37^{\circ} \mathrm{C}$ the slides were washed with PBS ( $\mathrm{pH} 7.3$ ) and incubated for another $30 \mathrm{~min}$ in the presence of a 1:40 dilution of FITC-conjugated goat IgG anti-mouse Ig (IgG $+\operatorname{IgM}+\operatorname{IgA}$ ) that was heavy and light chain specific (CAPPEL, Cochranville, PA). After washing the slides were mounted in $50 \%$ buffered glycerol and examined under the fluorescent microscope.

\subsection{Solid-phase radioimmunoassay (SRIA)}

Reactivity of polyvalent antisera against $L$. chagasi promastigote surface antigens was also measured by SRIA [13] which has been adapted for Leishmania spp. by McMahon-Pratt and David [14]. Briefly, $10^{6}$ fixed promastigotes in $50 \mu$ I PBS (pH 7.3) were coated in each well of a 96-well polyvinyl chloride microtiter plate (Cooks Lab. Prod., Alexandria, VA). The plates were saturated with $2 \%$ BSA in PBS (SRIA buffer) for $60 \mathrm{~min}$ at room temperature. Promastigotecoated wells were reacted with $50 \mu \mathrm{l}$ of serial dilutions of anti-3 day and anti- 5 day sera for $60 \mathrm{~min}$ at room temperature, washed in SRIA buffer and incubated for an additional $60 \mathrm{~min}$ at room temperature with $50 \mu \mathrm{l}$ of the goat $\mathrm{IgG}$ anti-mouse Ig (CAPPEL, Cochranville, PA) labelled with ${ }^{125} \mathrm{I}$. The plates were washed in SRIA buffer, air dried and the wells counted in a gamma counter.

\section{Results}

\subsection{Promastigote-macrophage interactions}

In our controlled cultures the promastigotes of $L$. chagasi and $L$. donovani remained in the active dividing phase (logarithmic) up to the 4th day and in the nondividing phase (stationary) for the 5th and 6th day. The promastigotes of day 3 and day 5 were selected for the present study.

Table 1 is a summary of results of Leishmania-macrophage interactions obtained with the promastigotes, procured from both log and stationary phases of in vitro cultures. An average $37 \% \mathrm{M} \varnothing$ showed the attachment of log phase promastigotes of $L$. chagasi at a ratio of 1:1. At the end of $24 \mathrm{~h}$ incubation, these promastigotes were seen to transform to amastigotes with $48 \%$ infection of MØ, but at the end of $48 \mathrm{~h}$ incubation there was no further increase in amastigotes. The total infection at this time remained almost constant. Most of the parasites were seen to be extracellular and degenerated. By contrast, promastigotes obtained on day 5 showed an increased adherence within 30 min of incubation. On subsequent incubation extensive transformation to amastigotes could be observed and the

Table 1

Leishmania-macrophage interactions in vitro in $\mathrm{BALB} / \mathrm{c}$ mouse $\mathrm{M} \varnothing$ at $37^{\circ} \mathrm{C}$

\begin{tabular}{|c|c|c|c|c|c|}
\hline \multirow[t]{2}{*}{$\begin{array}{l}\text { Leishmania } \\
\text { species }\end{array}$} & \multirow[t]{2}{*}{$\begin{array}{l}\text { Days in } \\
\text { culture }\end{array}$} & \multirow[t]{2}{*}{$\begin{array}{l}\% \text { Attachment } \\
\text { within } 30 \mathrm{~min}\end{array}$} & \multirow[t]{2}{*}{$\begin{array}{l}\text { No. of } \\
\text { promastigotes } \\
\text { per } 100 \mathrm{M} \varnothing\end{array}$} & \multicolumn{2}{|c|}{$\begin{array}{l}\text { No. of amastigotes per } \\
100 \mathrm{M} \varnothing \text { at different } \\
\text { time intervals }\end{array}$} \\
\hline & & & & $24 \mathrm{~h}$ & $48 \mathrm{~h}$ \\
\hline L. chagasi & $\begin{array}{l}3 \\
5\end{array}$ & $\begin{array}{l}37 \\
77\end{array}$ & $\begin{array}{l}102 \\
363\end{array}$ & $\begin{array}{r}75(48) \\
514(85)\end{array}$ & $\begin{aligned} 25 & (39) \\
633 & (94)\end{aligned}$ \\
\hline L. donovani & $\begin{array}{l}3 \\
5\end{array}$ & $\begin{array}{l}20 \\
27\end{array}$ & $\begin{array}{r}79 \\
145\end{array}$ & $\begin{array}{r}30(28) \\
803(88)\end{array}$ & $\begin{array}{r}50(23) \\
1740(98)\end{array}$ \\
\hline
\end{tabular}

a Count of 1000 cells.

Numbers in parentheses indicate $\% \mathrm{M} \varnothing$ infected. 
multiplication and reinfection at the end of $48 \mathrm{~h}$ was marked. Identical results were obtained in $L$. donovani-macrophage interactions.

\subsection{Reactivity of polyvalent immune sera to promastigotes}

The IFAT, using both log and stationary phase promastigotes as antigen models, indicated that polyvalent anti-sera reacted strongly with the surface of $L$. chagasi promastigotes in a homologous promastigote-antiserum system (Table 2). Bright fluorescence was observed up to a serum dilution of 1:320. Two anti-3 day sera from intradermal group of mice cross-reacted on the surface of day 5 promastigotes, but the fluorescence observed was discontinuous and irregular at a reciprocal titer of 1:80. However, anti-5 day promastigote sera failed to recognize the antigens on the surface of day 3 promastigotes.

The reactivity of the above sera was also evaluated in SRIA tests using promastigotes from in vitro cultures as well as from the sandfly vector. The level of reactivity was taken as a ratio of CPM bound in the presence of antibody to CPM bound by negative controls (Fig. 1). Anti-5 day sera reacted strongly with the promastigotes of sandfly origin, with an elevated ratio of CPM-bound antibody as compared to anti-3 day sera.

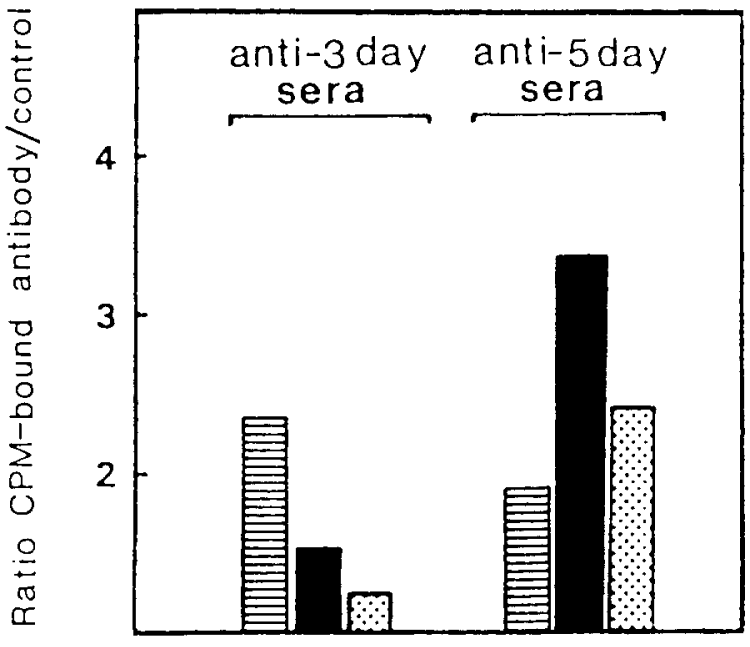

\section{Promastigotes}

Fig. 1. Evaluation of the specificities of polyclonal antibodies in SRIA using glutaraldehyde fixed promastigotes of $L$. chagasi as antigen. stationary phase promastigotes (day 5); 7 , late stage sandfly promastigotes.

\subsection{Effect of polyvalent immune sera on in- tracellular survival of Leishmania in vitro}

Table 3 summarizes the effects of polyvalent mouse antisera against the logarithmic and stationary phase promastigotes on in vitro attach-

Table 2

Surface antigenic specificities of logarithmic and stationary phase promastigotes of L. chagasi by means of IFAT

\begin{tabular}{lllc}
\hline $\begin{array}{l}\text { Route of } \\
\text { immunization }\end{array}$ & Sera of mice & \multicolumn{2}{l}{$\begin{array}{l}\text { Reciprocal IFA titers with fixed } \\
\text { promastigotes of }\end{array}$} \\
\cline { 3 - 4 } & & $\begin{array}{l}\text { Logarithmic } \\
\text { phase }\end{array}$ & $\begin{array}{c}\text { Stationary } \\
\text { phase }\end{array}$ \\
\hline Subcutaneous & anti-3 day & 320 & 40 \\
anti-5 day & 40 & 640 \\
Intradermal & anti-3 day & 640 & $80^{\mathrm{a}}$ \\
anti-5 day & 40 & 640 \\
\hline
\end{tabular}

a Fluorescence sparse and irregular. 
Table 3

Survival of $L$. chagasi treated with polyclonal mouse antisera against logarithmic and stationary phase promastigotes in mouse peritoneal macrophages in vitro

\begin{tabular}{lllll}
\hline $\begin{array}{l}\text { Antibody } \\
\text { treatment }\end{array}$ & $\begin{array}{l}\text { \% Attachment } \\
\text { within } 30 \mathrm{~min}\end{array}$ & $\begin{array}{l}\text { No. of } \\
\text { promastigotes } \\
\text { per 100 MØ }\end{array}$ & $\begin{array}{l}\text { No. of amastigotes per } \\
100 \mathrm{M} \varnothing \text { at different time } \\
\text { intervals }\end{array}$ \\
\hline $\begin{array}{l}\text { Anti-3 day } \\
\text { serum }\end{array}$ & 84 & 503 & $24 \mathrm{~h}$ & $48 \mathrm{~h}$ \\
$\begin{array}{l}\text { Anti-5 day } \\
\text { serum }\end{array}$ & 82 & 468 & $271(84)$ & $527(76)$ \\
$\begin{array}{l}\text { Normal mouse } \\
\text { serum }\end{array}$ & 85 & 338 & $202(44)$ & $103(45)$ \\
\hline $\begin{array}{l}\text { a Count of } 1000 \text { cells. } \\
\text { Numbers in parentheses indicate } \%\end{array}$ & MO infected. & & $2349(95)$ \\
\hline
\end{tabular}

ment, uptake and intracellular survival of infective $L$. chagasi in normal BALB/c mouse peritoneal MØ. Neither anti-3 day nor anti-5 day sera were found to interfere with the attachment of promastigotes to $\mathrm{M} \varnothing$ compared with the controls. The treatment of promastigotes with anti-3 day or anti-5 day sera partially abolished their capacity to multiply within the $\mathbf{M} \varnothing$ in vitro. The inhibitory effect of anti-5 day serum on the multiplication of intracellular amastigotes was noticeable only at the end of $48 \mathrm{~h}$ incubation, when only $45 \%$ of cells exhibited morphologically intact amastigotes. At the same time, there was a considerable decrease in the number of intact intracellular amastigotes, with a concomitant increase of degenerate and extracellular parasites.

However, in MØ infected with anti-3 day serum-treated promastigotes there was an initial decrease in the number of intracellular amastigotes, but the parasites already internalized were seen to multiply at the end of $48 \mathrm{~h}$ incubation. Further, there was no marked alteration in the overall infection of MØ.

\section{Discussion}

In the present study we have demonstrated by IFAT and SRIA, using polyclonal antibodies, that surface antigenic expression of infective Leishmania promastigotes (stationary forms) is different from that of noninfective (logarithmic forms) parasites.

A clear differentiation of a non-infective and an infective population was observed in promastigote cultures of $L$. chagasi and $L$. donovani. These results support those obtained with $L$. tropica [10]. Some promastigotes of the $\log$ phase were found to infect the $M \varnothing$ and develop into amastigotes (Table 1). This can be attributed to the passage of infective promastigotes to subcultures, and which would have neither multiplied nor died when the parasites were introduced to MØ. However, the multiplication of $\log$ phase promastigotes within the M $\varnothing$ and overall $\mathrm{M} \varnothing$ infection at the end of $48 \mathrm{~h}$ incubation was not significant compared with stationary phase (day 5) promastigotes. The promastigote/MØ ratio in our experiments, selected to yield moderate infection, was found to be independent of the number of intracellular parasites, because the non-adherent promastigotes were washed off after $4 \mathrm{~h}$ incubation.

The in vitro development of infective forms seems to be similar to the developmental changes occurring during the growth of promastigotes in sandfly vector [9]. Inoculation of promastigotes from the sandfly has repeatedly been shown to initiate infection in susceptible hosts $[9,12,15,16]$. There were, however, some reports 
of failure to establish infections [9]. Moreover, several investigators have found a correlation between the age of Leishmania promastigotes in cultures and their infectivity for experimental animals [15]. The generation of an infective form with modified surface molecules in the sandfly suggests that the nutrient-depleted environment, resembling that of stationary cultures, exerts a selective pressure on the promastigotes, thereby giving rise to an infective form possibly resistant to enzyme degradation within the MØ. In fact, the labelled surface molecules of Leishmania parasites were shown to persist up to $36 \mathrm{~h}$ within the MØ without being digested [17].

In this study, we also attempted to show that modifications in antigenic expression may arise during the development of Leishmania promastigotes. Polyclonal antibodies against the promastigotes in the log and stationary phases bound specifically to the surface of their corresponding populations in both SRIA and IFAT. A weak positive reactivity was noticed between promastigotes of the stationary phase and some anti-3 day sera. This can be attributed to few common antigenic determinants shared by these two populations. In fact, during the sequential development, the promastigotes in the stationary phase could have retained certain antigens characteristic of log phase promastigotes. There was, however, no binding of fluorescent antibodies of anti-5 day sera to logarithmic phase promastigotes. This clearly indicates the appearance of new antigenic molecules on the surface of infective promastigote forms. The ability of anti-3 day and anti-5 day sera to recognize specifically their corresponding antigens was specially observed with mice immunized early (about $4 \mathrm{wk}$ ). This phenomenon was found to diminish when the same groups of mice were immunized for an extended period (data not shown), and strong cross-reactions were observed. It seems that major common antigens dominate only during late immune responses in $\mathrm{BALB} / \mathrm{c}$ mice. Moreover, this suggests that antigenic determinants recognized by anti- 3 day sera are not sufficiently immunogenic on the surface of stationary phase promastigotes during early 28 days of immunization.
Efficient binding of anti-5 day but not anti-3 day antibodies was found, too, on the surface of day 7 promastigotes obtained from the sandfly. This provides direct evidence for similarities of in vitro stationary phase and late stage (day 7) sandfly promastigotes both in their ability to infect macrophages and in their antigens. Also, it may be possible that anti-3 day sera would cross-react with early stage sandfly promastigotes.

The preliminary results on the capacity of polyclonal antisera to block the Leishmaniamacrophage interactions provide indirect evidence for cell surface modifications during in vitro infective promastigote differentiation. The inhibitory effect of both anti- 3 and anti- 5 day sera seems to be due to the antibodies against antigenic determinants shared by both infective and non-infective promastigotes and are involved only in the primary interaction of parasites with host cells. In fact, anti-3 day serum treated promastigotes already transformed to amastigotes were seen to thrive and multiply in MØ over a $48 \mathrm{~h}$ incubation period. The inhibitory effect was more pronounced in $M \varnothing$ infected with anti-5 day serum-treated promastigotes. There was a considerable decrease both in the number of intracellular amastigotes and in the overall infection of MØ compared with anti-3 day serum. It can be argued that the dominance of infective stage-specific antibodies in anti-5 day sera largely contributes to the decrease in intracellular parasites and to the subsequent inhibition of reinfection as well. This variability in the extent of inhibitory activities of immune sera further supports the above findings of modification or appearance of new molecules on the surface of infective promastigotes that may be involved in the transformation and/or intracellular survival of $L$. chagasi.

However, neither anti-3 day nor anti-5 day sera were found to interfere with promastigote attachment to MØ within $\mathbf{3 0}$ min. This is because the attachment of particulate entities such as promastigotes and monocytes entails highly complex interactions, possibly involving electrostatic and hydrophobic forces [18]. As a result, antibodies may not be sufficient to mask the specific 
ligands involved in the attachment process or to alter the cell surface in a non-specific manner.

In conclusion, promastigotes of Leishmania spp. develop into an infective stage both in cultures as well as in sandfly vectors. This

phenomenon simultaneously gives rise to modifications in the expression of cell-surface antigens of the infective forms. Such modified antigenic expression may facilitate parasite adherence to, and penetration into, the macrophages and could contribute to the protection of leishmaniae in the hostile activities of host cells. The immediate implication of these findings is that this diversity will have to be taken into consideration when vaccines are developed against leishmanial infections. The development of specific antibodies against isolated new antigenic molecules from the surface of infective promastigotes will be a critical step in blocking Leishmania-MØ interactions, and such antibodies can be used as molecular markers to identify and characterize infective leishmanial forms.

\section{Acknowledgements}

We acknowledge the expert technical assistance of Didier Deslée, Marc Loyens and Vera Vidal, and the secretarial help of Claudine Colson and Marie-France Massard. This investigation received financial support from The Rockefeller Foundation, UNDP/World Bank/WHO Special Programme for Research and Training in Tropical Diseases and EEC (grant no. TSD-M-010-F (RS)).

\section{References}

[1] Zuckerman, A. and Lainson, R. (1977) in: Parasitic Protozoa (J. P. Krier, Ed.), Vol. 1, pp. 57-133, Academic Press, New York.

[2] Alexander, J. and Vickerman, K. (1975) J. Protozool. $22,502$.

[3] Bray, R. S. (1974) Ann. Rev. Microbiol. 28, 189.

[4] Bray, R. S. (1983) J. Protozool. 30, 314.

[5] Chang, K. P. and Dwyer, D. M. (1975) J. Parasitol. 61 (Suppl.), 71.

[6] Chang, K. P. and Dwyer, D. M. (1978) J. Exp. Med. $147,513$.

[7] Chang, K. P. (1979) Exp. Parasitol. 48, 175.

[8] Akiyama, H. J. and Haight, R. D. (1971) Am. J. Trop. Med. Hyg. 20, 539.

[9] Killick-Kendrick, R. (1979) in: Biology of the Kinetoplastida (W. H. R. Lumsden and D. A. Evans, Eds.) pp. 395-460, Academic Press, London.

[10] Sacks, D. L. and Perkins, P. V. (1984) Science 223, 1417.

[11] Jadin, J. B. and Pierreux, G. (1960) Ann. Soc. Belge Med. Trop. 40, 903.

[12] Lainson, R., Ward, R. D. and Shaw, J. J. (1977) Nature $266,628$.

[13] Stocker, J. W. and Heusser, C. H. (1979) J. Immunol. Methods 26, 87.

[14] McMahon-Pratt, D. and David, J. R. (1981) Nature (London) 291, 581.

[15] Adler, S. (1964) Adv. Parasitol. 2, 35.

[16] Giannini, M. S. (1974) J. Protozool. 21, 521.

[17] Chang, K. P. and Fong, D. (1983) in: Cytopathology of Parasitic Diseases (D. Evered and G. M. Collins, Eds.) pp. 113-137, Pitman Books, London.

[18] Keush, G. T. (1982) in: Current Topics in Inflammation and Infection (G. Majno, R. S. Cotran and N. Kaufman, Eds.) pp. 98-113, The Williams and Wilkins Co., Baltimore. 